\title{
Exploring the relationship between vegetation and dust-storm intensity (DSI) in China
}

\author{
TAN Minghong
}

Key Laboratory of Ecosystem Network Observation and Modeling, Institute of Geographic Sciences and Natural Resources Research, CAS, Beijing 100101, China

\begin{abstract}
It is difficult to estimate the effects of vegetation on dust-storm intensity (DSI) since land surface data are often recorded aerially while DSI is recorded as point data by weather stations. Based on combining both types of data, this paper analyzed the relationship between vegetation and DSI, using a panel data-analysis method that examined six years of data from 186 observation stations in China. The multiple regression results showed that the relationship between changes in vegetation and variance in DSI became weaker from the sub-humid temperate zone (SHTZ) to dry temperate zone (DTZ), as the average normalized difference vegetation index decreased in the four zones in the study area. In the SHTZ and DTZ zones, the regression model could account for approximately $24.9 \%$ and $8.6 \%$ of the DSI variance, respectively. Lastly, this study provides some policy implications for combating dust storms.
\end{abstract}

Keywords: relationship; dust-storm intensity; land surface feature; northern China

\section{Introduction}

Dust events exert various impacts on radiative forcing, human health, and agricultural production (Cyranoski, 2003; Prospero and Lamb, 2003; Prospero et al., 2012), and dust can be transported over thousands of kilometers (Fischer et al., 2009; Tan et al., 2012). So, the changes in dust-storm intensity (DSI) and the causative factors have been a central focus of much global research. In the existing literature, DSI is expressed by different measures. First, dust-storm frequency (DSF) is widely used as a measure of dust activity over a range of time scales (McTainsh et al., 2005; Yang et al., 2007; Goudie, 2009; Wang et al., 2004; Yumimoto et al., 2010; Liu and Liu, 2015). Second, the duration of dust storms has been used as a measure by some authors (Liu and Park, 2007); for example, Yao et al. (2011) analyzed the spatial differences in durations of dust storms in the Alxa Plateau of China from 1961 to 2005. Third, dust visibility or the concentration of dust is also used as a measure of DSI (McTainsh et al., 1998). Based on these studies, it is easy to infer that DSI has a

Received: 2015-03-18 Accepted: 2015-11-05

Foundation: National Natural Science Foundation of China, No.41271119, No.91325302; No.41161140352; National Basic Research Program of China, No.2015CB452705

Author: Tan Minghong, PhD and Associate Professor, E-mail: tanmh@igsnrr.ac.cn 
close relationship with frequency, duration, and visibility of dust storms. Thus, some studies provide comprehensive measures of the intensity of dust storm (McTainsh et al., 2011; O'Loingsigh et al., 2014). For example, McTainsh et al. (2011) provide a composite measure of the intensity of dust storm, using the World Meteorological Organization's (WMO) SYNOP codes. Tan et al. (2014) define the DSI of China by considering the frequency, duration, and visibility of dust storms.

The changes in DSI are affected by various factors including precipitation, temperature, wind speed, soil moisture (Prospero and Lamb, 2003; Gong et al., 2004; McTainsh et al., 2005; Yang et al., 2007). When examining these factors further, this study thinks that both land surface (e.g., dust source and low ground surface coverage) (Yang et al., 2007) and wind speed directly affect DSI (Xiao et al., 2008) (Figure 1). Human activities and environmental variables (e.g., precipitation, temperature) are mainly responsible for changes in vegetation and land surface (Xu et al., 2006; Cook et al., 2009; Wang et al., 2009).

In earlier studies, the effect of climatic factors on DSF has attracted much attention, and factors such as precipitation, temperature, and wind speed have been quantitatively measured (McTainsh et al., 1998; Shao and Dong, 2006; Zhu et al., 2008) since they are all point data recorded by meteorological observation stations. In contrast, the effect of vegetation on dust storm activity has often been ignored, principally because dust events are often recorded as point data, while vegetation are recorded as aerial data. At present, little literature

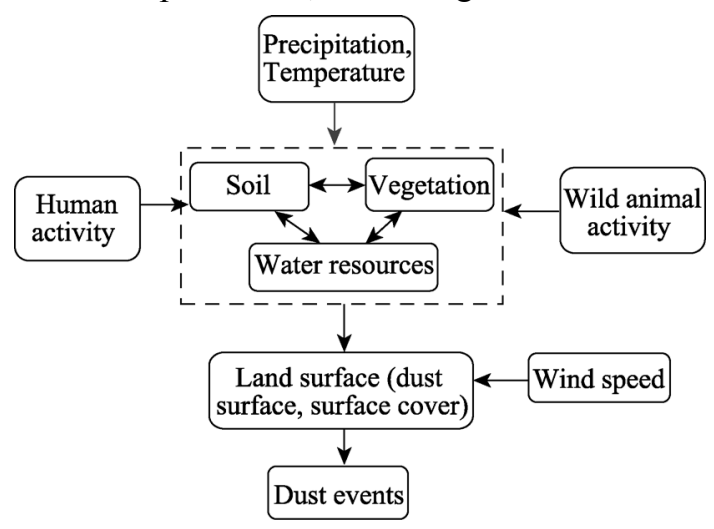

Figure 1 The factors causing changes in DSI is focused on the effects of vegetation on DSI, although a few earlier studies have examined the relationship between vegetation and DSF (Engelstaedter et al., 2003; $\mathrm{Xu}$ et al., 2006).

Thus, this study calculated DSI in China, considering the frequency, duration, and visibility of dust events. Then, the relationship between vegetation and DSI was analyzed by combining the point data (DSI) and aerial data (vegetation), using multiple regression model.

\section{Data and methods}

\subsection{Data}

In this study, dust-storm data were gathered from 186 meteorological observation stations run by the China Meteorological Administration (CMA) (Figure 2). The data included geographical location of each observation station, wind speed, wind direction, the start and end times, and the visibility of each dust-storm event.

Vegetation indices such as the normalized difference vegetation index (NDVI) provide a much clearer description of vegetation (Kimura, 2012). In this paper, the NDVI remote sensing data were obtained from the National Oceanic and Atmospheric Administration's (NOAA) Advanced Very High Resolution Radiometer (AVHRR). The NDVI index consists of bi-weekly composite images at 8-km resolution. 


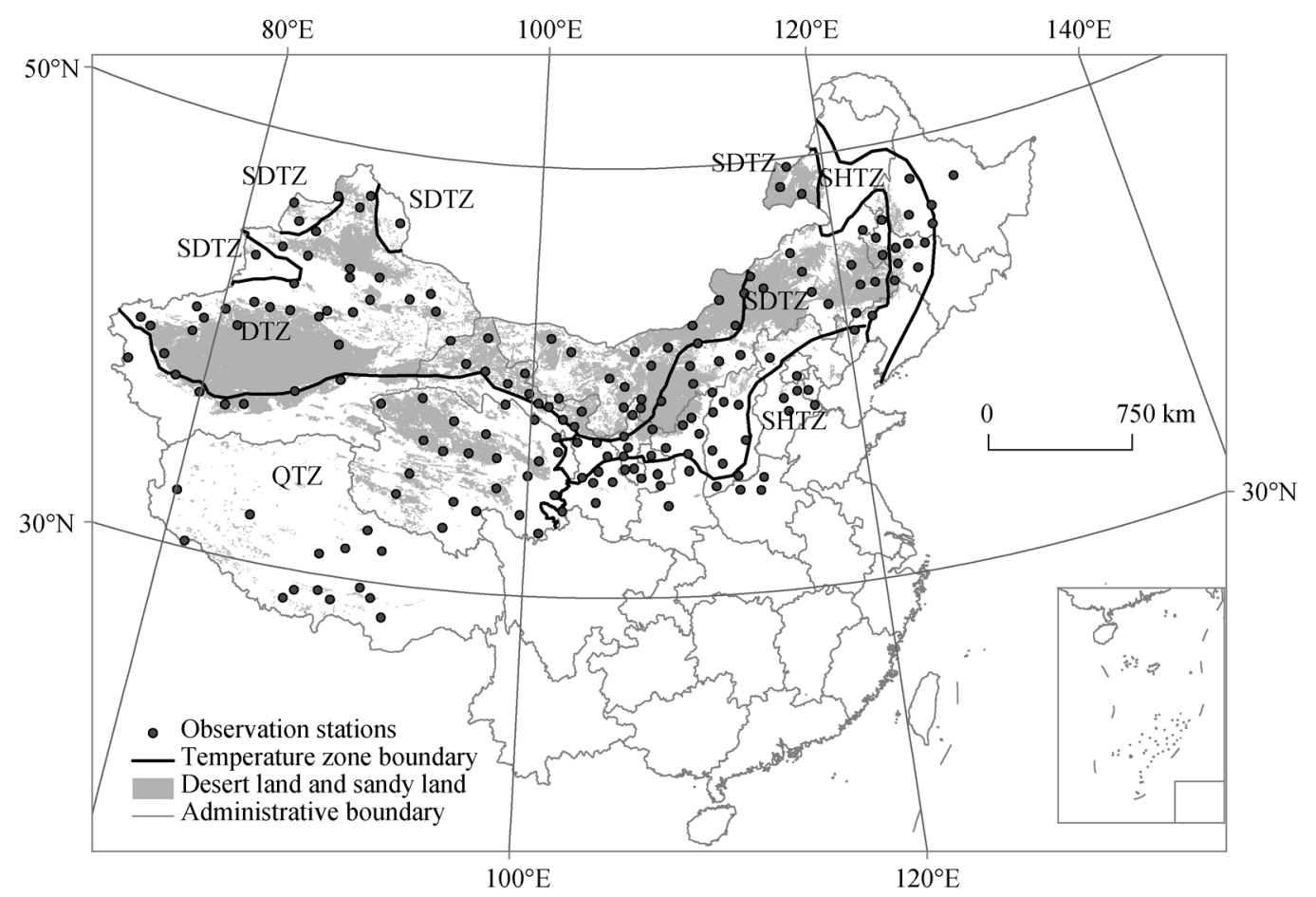

Figure 2 The distribution of 186 weather stations and desert land and sandy land, and the division of temperature zones in China. Note: The distribution map of desert land and sandy land in China is from the EESDC (2013).

\subsection{Division of the temperature zone}

Considering the vast differences in NDVI in different regions in northern China, this study divided the stations into four categories: SHTZ, semi-dry temperate zone (SDTZ), DTZ and Qinghai-Tibet zone (QTZ) (Figure 2). Thus, to analyze the effects of the NDVI on the DSI, four multiple regression models were developed in the above zones respectively. In each model, the selected variables were entered as a block in a single step of the SPSS software program.

\subsection{Definition of DSI}

According to the study by Tan et al. (2014), the sum value of the DSIs $\left(S D S I_{j}\right)$ of all dust events recorded by a station in year $j$ can be expressed by the following equation:

$$
S D S I_{j}=\sum_{i=1}^{n}\left(D U R A_{i}^{j} \times \frac{1}{V I S I B_{i}^{j}}\right)
$$

where $D U R A_{i}^{j}$ is the duration of dust event $i$ at the station in year $j$, calculated with the end time and start time of the dust event, and $V I S I B_{i}^{j}$ is the visibility (in meters) of dust event $i$ at the station in year $j$.

The CMA provided the dust event data from 1980 to 2007. Based on equation (1), the average value for SDSI across all 186 stations for each year can be calculated in this study. According to the time-series curve of SDSI, this study selected six years' data $(1983,1988$, 
1993, 1998, 2003 and 2006) from 186 observation stations to examine the changes in NDVI and the effects on DSI, using a panel data-analysis method.

\subsection{Combining the DSI and NDVI data}

To combine the DSI and NDVI data, this study firstly built five buffers at $10 \mathrm{~km}, 20 \mathrm{~km}, 30$ $\mathrm{km}, 40 \mathrm{~km}$ and $50 \mathrm{~km}$ from each station (Figure 3). Then, this study calculated the average values of the NDVI in the spring and the summer at the 5 buffers, respectively. Using a bivariate correlation model of an SPSS software package, the correlation coefficients of the DSI and the NDVI values were calculated. The model showed that the NDVI had a closer association with the DSI both in the spring and the summer in the 20 -km buffer than in the other buffers. Thus, this study selected the NDVI variable in the $20-\mathrm{km}$ buffer as the independent variable to explain the effect of the NDVI on the DSI (Table 1).

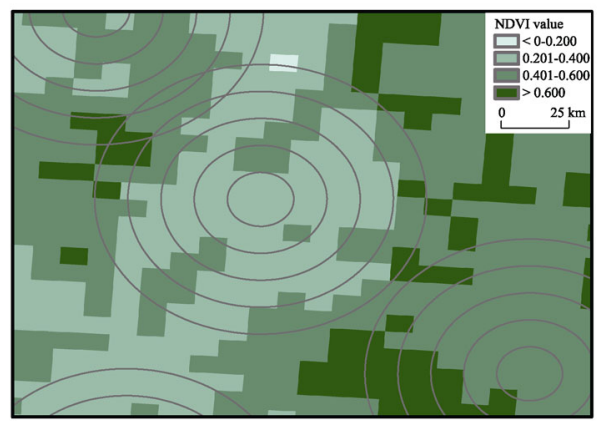

Figure 3 The NDVI values in five buffers

Table 1 Correlations between NDVI and DSI in the different buffers

\begin{tabular}{|c|c|c|c|c|c|c|c|c|c|c|c|}
\hline & $S D S I$ & $S p r_{-} 10$ & Sum_10 & Spr_20 & Sum_20 & Spr_30 & Sum_30 & $S p r_{-} 40$ & Sum_40 & Spr_50 & Sum_50 \\
\hline$S D S I$ & 1 & -0.168 & -0.272 & -0.172 & -0.273 & -0.166 & -0.273 & -0.163 & -0.271 & -0.158 & -0.263 \\
\hline Spr_10 & & 1 & 0.666 & 0.968 & 0.674 & 0.945 & 0.658 & 0.928 & 0.647 & 0.895 & 0.621 \\
\hline Sum_10 & & & 1 & 0.648 & 0.967 & 0.628 & 0.932 & 0.624 & 0.909 & 0.602 & 0.853 \\
\hline Spr_20 & & & & 1 & 0.702 & 0.987 & 0.695 & 0.974 & 0.687 & 0.943 & 0.660 \\
\hline Sum_20 & & & & & 1 & 0.690 & 0.977 & 0.691 & 0.959 & 0.671 & 0.904 \\
\hline Spr_30 & & & & & & 1 & 0.710 & 0.995 & 0.708 & 0.979 & 0.697 \\
\hline Sum_30 & & & & & & & 1 & 0.718 & 0.993 & 0.718 & 0.969 \\
\hline Spr_40 & & & & & & & & 1 & 0.724 & 0.990 & 0.717 \\
\hline Sum_40 & & & & & & & & & 1 & 0.727 & 0.982 \\
\hline Spr_50 & & & & & & & & & & 1 & 0.741 \\
\hline Sum_50 & & & & & & & & & & & 1 \\
\hline
\end{tabular}

Note: Correlation is significant at the 0.01 level (2-tailed) for all variables. The variables from $S p r+10$ to $S p r \quad 50$ in this table, were the average values of NDVI in the spring from $10 \mathrm{~km}$ to $50 \mathrm{~km}$ buffers, respectively. Similarly, the variable from Sum_10 to Sum_50 are the values in the summer in the previous year from $10 \mathrm{~km}$ to $50 \mathrm{~km}$ buffers, respectively. The variable of SDSI was calculated using the equation (1). The correlation coefficients of the DSI and the NDVI values were calculated, using a bivariate correlation model of an SPSS software package.

In the western and northern plateau areas in the study region, the low temperature and high altitude created a shorter growing season (July and August) (Duan et al., 2011). In August, the NDVI levels increased to a maximum value. Thus, the average values in July and August were therefore selected to represent the NDVI in the summer for the previous year, since vegetation components (roots, humus, etc.) in these two months can influence the soil texture during the subsequent winter months ( $\mathrm{Xu}$ et al., 2006). In addition, because about $70 \%$ of the dust events occurred in March, April and May, the average of the NDVI values for these three months was then regarded as representative of the NDVI value for the spring 
of the current year.

As linearity is necessary in multiple regression analysis, this paper used logarithms of the independent variables, including the average NDVI values of summer (LnSum_20) and spring ( $\left.L n S p r \_20\right)$ in the 20-km buffer (Table 2). Given that an NDVI value may vary across grids in a buffer (Figure 3), the standard deviation values of the NDVI in the summer (Sum_20STD) and the spring (Spr_20STD) were regarded as independent variables (Table 2). The two variables were used to measure how much variation or dispersion from the average values of all grids in a buffer. A low value of standard deviation indicates that the data grids tend to be closer to the mean.

Table 2 The results of multi-regression analysis in different temperature zones of China

\begin{tabular}{|c|c|c|c|c|c|c|c|c|}
\hline & \multirow[t]{2}{*}{ Model } & \multicolumn{2}{|c|}{$\begin{array}{l}\text { Non-standardized } \\
\text { coefficients }\end{array}$} & \multirow{2}{*}{$\begin{array}{c}\begin{array}{c}\text { Standardized } \\
\text { coefficients }\end{array} \\
\text { Beta }\end{array}$} & \multirow[t]{2}{*}{$t$} & \multirow[t]{2}{*}{ Sig. } & \multicolumn{2}{|c|}{$\begin{array}{l}\text { Collinearity } \\
\text { statistics }\end{array}$} \\
\hline & & B & Std. Error & & & & Tolerance & VIF \\
\hline \multirow{7}{*}{ SHTZ } & (Constant) & 408.026 & 208.969 & & 1.953 & 0.052 & & \\
\hline & LnSum_20 & -58.358 & 24.968 & -0.145 & -2.337 & 0.020 & 0.936 & 1.068 \\
\hline & LnSpr_20 & -15.210 & 27.548 & -0.050 & -0.552 & 0.581 & 0.430 & 2.326 \\
\hline & Sum_20STD & -0.008 & 0.266 & -0.002 & -0.029 & 0.977 & 0.852 & 1.174 \\
\hline & $S p r_{-} 20 S T D$ & 0.057 & 0.521 & 0.010 & 0.110 & 0.912 & 0.407 & 2.457 \\
\hline & Wind & 1.867 & 1.016 & 0.126 & 1.838 & 0.068 & 0.759 & 1.318 \\
\hline & $V_{-} 1983$ & 133.383 & 19.339 & 0.427 & 6.897 & 0.000 & 0.936 & 1.068 \\
\hline \multirow{7}{*}{ SDTZ } & (Constant) & 2179.793 & 375.277 & & 5.808 & 0.000 & & \\
\hline & LnSum_20 & -245.668 & 56.350 & -0.288 & -4.360 & 0.000 & 0.626 & 1.598 \\
\hline & Lnspr_20 & -112.639 & 83.428 & -0.108 & -1.350 & 0.178 & 0.427 & 2.341 \\
\hline & Sum_20STD & -1.764 & 0.733 & -0.157 & -2.406 & 0.017 & 0.639 & 1.566 \\
\hline & Spr_20STD & 1.891 & 1.329 & 0.112 & 1.423 & 0.156 & 0.444 & 2.253 \\
\hline & Wind & 0.002 & 0.009 & 0.009 & 0.167 & 0.868 & 0.993 & 1.007 \\
\hline & $V_{-} 1983$ & 113.965 & 48.431 & 0.126 & 2.353 & 0.019 & 0.952 & 1.050 \\
\hline \multirow{7}{*}{ DTZ } & (Constant) & 119.356 & 217.082 & & 0.550 & 0.583 & & \\
\hline & LnSum_20 & -113.267 & 62.578 & -0.250 & -1.810 & 0.071 & 0.141 & 7.094 \\
\hline & Lnspr_20 & 104.619 & 87.193 & 0.152 & 1.200 & 0.231 & 0.167 & 5.984 \\
\hline & Sum_20STD & 0.852 & 0.695 & 0.143 & 1.225 & 0.221 & 0.198 & 5.053 \\
\hline & Spr_20STD & -2.589 & 1.327 & -0.193 & -1.951 & 0.052 & 0.274 & 3.644 \\
\hline & Wind & 4.344 & 1.878 & 0.164 & 2.313 & 0.021 & 0.537 & 1.863 \\
\hline & $V_{-} 1983$ & 85.220 & 46.245 & 0.100 & 1.843 & 0.066 & 0.912 & 1.096 \\
\hline \multirow{7}{*}{ QTZ } & (Constant) & 1331.376 & 275.143 & & 4.839 & 0 & & \\
\hline & LnSum_20 & -245.585 & 70.107 & -0.458 & -3.503 & 0.001 & 0.19 & 5.251 \\
\hline & Lnspr_20 & 36.739 & 109.948 & 0.044 & 0.334 & 0.739 & 0.184 & 5.421 \\
\hline & Sum_20STD & 0.93 & 1.166 & 0.072 & 0.798 & 0.426 & 0.396 & 2.524 \\
\hline & $S p r_{-} 20 S T D$ & 2.247 & 2.338 & 0.092 & 0.961 & 0.338 & 0.354 & 2.822 \\
\hline & Wind & -8.675 & 3.019 & -0.184 & -2.873 & 0.004 & 0.79 & 1.266 \\
\hline & $V_{-} 1983$ & 118.291 & 70.748 & 0.102 & 1.672 & 0.096 & 0.87 & 1.15 \\
\hline
\end{tabular}

Note: 1) The values of adjusted $R^{2}$ in the SHTZ, SDTZ, DTZ and QTZ models were 0.249, 0.168, 0.086 and 0.165, respectively. 2) The tolerance is a measure of collinearity reported by SPSS software. A small value indicates that a predictor is redundant. The VIF is $1 /$ tolerance. 
In 1983, the DSI was significantly higher than that in the other years, so the dummy variable (V_1983) for 1983 was incorporated into the regression model. As discussed above, wind and vegetation directly affect the DSI. Thus, the average of annual wind speed (Wind) was selected as an independent variable in this study.

\section{Results and discussion}

\subsection{Changes in DSI}

The results show significant spatial differences in SDSI values in different sub-periods at the 186 stations. In spatial distribution, SDSIs of higher values were located mainly in the DTZ (Figure 4) - for instance, around the Mu Us Desert and Hobq Desert and the southern edge of the Taklimakan Desert in Xinjiang (Figures 2 and 4). For most observation stations, in 1983, the DSI values were much higher than those in the other years. However, Onqin Daq Desert in Inner Mongolia became one of the regions with the highest DSI value in 2006.

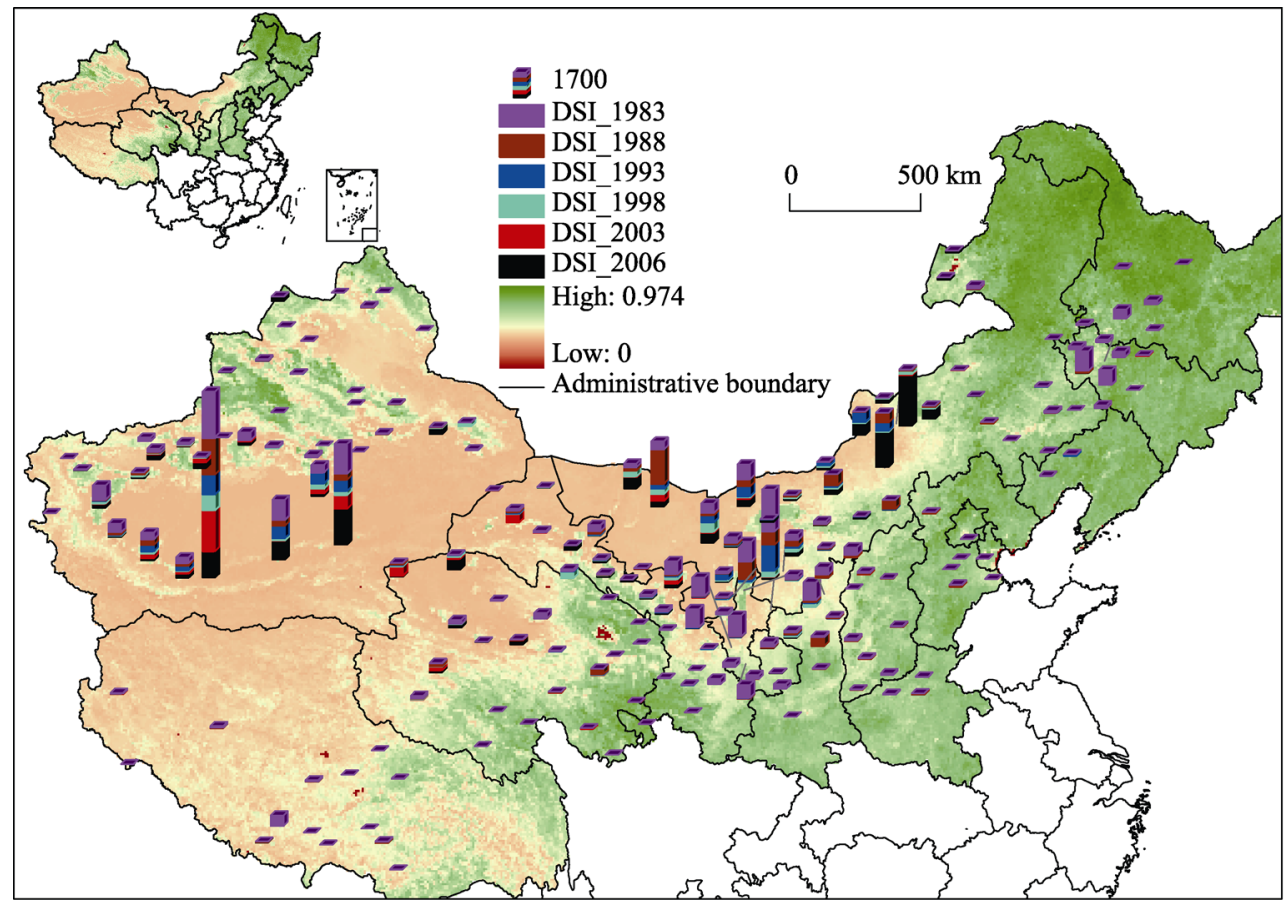

Figure 4 The values of SDSI in 1983, 1988, 1993, 1998, 2003 and 2006 at the 186 stations, and the distribution of the NDVI in the summer of 2005 in northern China

\subsection{Relationship between NDVI and DSI}

Improvement in vegetation cover can modify surface energy fluxes and water balance (D'Odorico et al., 2013), fix dunes, and reduce wind speeds (Torita and Satou 2007), thereby reduce DSI.

Table 2 also shows that LnSum_20 had a negative effect on the DSI in all the four models. This implied that the DSI decreased as the condition of the vegetation improved in the summer of the previous year. This is consistent with the study of $\mathrm{Xu}$ et al. (2006) which 
thinks vegetation components in the summer can influence the soil texture and dust activities during the subsequent winter months. On the contrary, in the four models, the LnSpr 20 had no close association with the DSI, which meant that the condition of the vegetation in the spring had no significant effects on DSI. The main reason is that the changes in the NDVI values could not been fully reflected in the spring, since the two months in March and April are not the growing season in many areas in the study re-

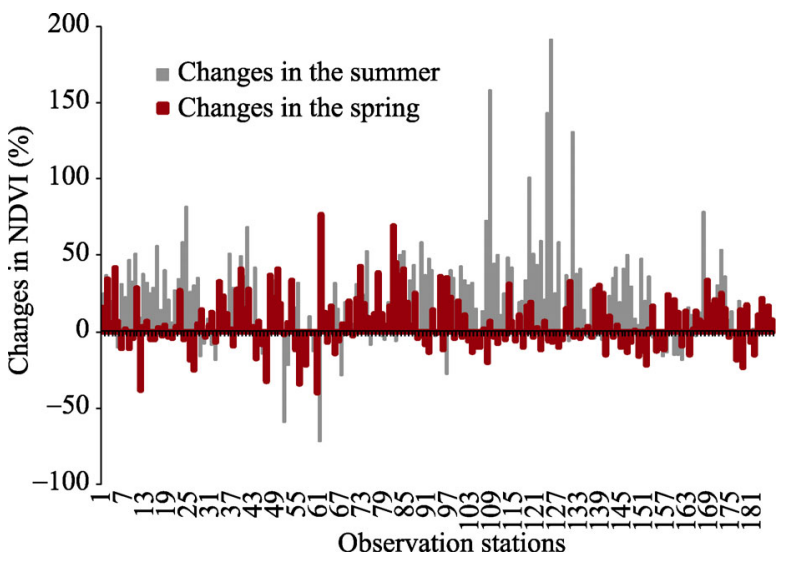

Figure 5 The changes in the average NDVI values in the 20-km buffer of 186 stations from 1983 to 2003 gion mainly due to low temperature. In addition, Figure 5 shows that the changes in the NDVI values in the summer were much larger than that in the spring. The average of the NDVI values in the $20-\mathrm{km}$ buffer of 186 stations increased by $19.4 \%$ in the summer from 1983 to 2003 , while the value only increased by $4.3 \%$ in the spring. The more rapid improvement in the summer may have more significant effects on the DSI.

This is different from the existing literature. For instance, Liu et al. (2004) think the vegetation condition in the spring has a close relationship with the variation pattern of the spring DSF in northern China. In the study, the researchers do not discuss the effects of the vegetation condition in the summer on DSF.

In addition, in the SDTZ model only, the standard deviation of the NDVI in the summer (Sum_20STD) had a significant negative effect on the DSI, which meant that a uneven distribution of vegetation could decrease the DSI in the SDTZ. Similarly, in the DTZ model only, the standard deviation of the NDVI in the spring (Spr_20STD) had a negative relationship with the DSI at a $10 \%$ level of significance.

In all models, the dummy variable of $V_{-} 1983$ had a significant positive relationship with the dependent variable, since the DSI values in 1983 were much higher than those in the other years.

The Wind variable had significant influence on the DSI, except in the SDTZ model. In this study, the wind speed was the annual average value at every observation station, because it is difficult to obtain the wind speed data for every dust event. This may distort the true effect of wind speed on DSI, which may be one of the reasons that the Wind variable had no significant effect on the DSI in the SDTZ model. In the existing literature, strong wind is often regarded as one of three conditions for the formation of dust storms as well low ground surface coverage and rich dust source (Yang et al., 2007; Xiao et al., 2008). In the future study, it is necessary to collect the wind speed data for every event during the study of DSI.

Moreover, there is a clear relationship between the NDVI and the variance in DSI-the relationship weakened as the average NDVI value decreased in the four zones (Figure 6). Specifically, the average NDVI values in summer declined from 0.498 in the SHTZ zone to 0.227 in the DTZ zone for the selected six years, respectively. Correspondingly, the adjusted 


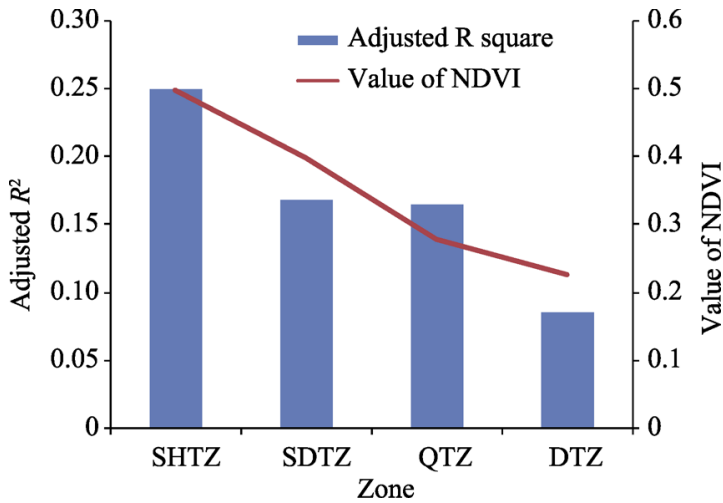

Figure 6 The average values of NDVI and the relationship between the NDVI and DSI in the DSI SHTZ, SDTZ, QTZ and DTZ models

$R^{2}$ values decreased from 0.249 in the SHTZ model to 0.086 in the DTZ model (Figure 6). Thus, the relationship between the NDVI and the DSI was strongest in the SHTZ model, and weakest in the DTZ model (Table 1). The SHTZ and DTZ models accounted for approximately $24.9 \%$ and $8.6 \%$ of the variance in DSI, respectively. Previous studies have shown similar results: the improved condition of the vegetation in the Chinese deserts within $200 \mathrm{~mm} / \mathrm{y}$ and $400 \mathrm{~mm} / \mathrm{y}$ precipitation zones decreased the surface dust concentrations by $10 \%-50 \%$ in most regions, using the Northern Aerosol Regional Climate Model for analyzing the distribution of dust storms in 2001 (Gong et al., 2004).

The above discussion can provide some policy implications for combating desertification and reducing the damage of dust storms. In northern China, the vegetation improvement can more effectively decreased DSI, especially in the areas with high vegetation index, for instance in SHTZ. Furthermore, because these areas often have a higher population density and strong human activities, dust storms often cause more extensive damage, compared with the areas with low vegetation index (e.g., in dry temperate zone). Therefore, it may be more urgent and effective to strengthen reforestation and re-vegetation in these areas to decrease DSI and reduce the damage caused by dust events in the areas with a high vegetation index in northern China, such as in the zone of SHTZ.

In addition, using the same dust-storm data from the CMA, the previous-year precipitation and temperature can only explain about $5 \%$ of the changes in DSI (Tan et al., 2014). So, it would appear that vegetation may have a stronger effect on DSI than precipitation and temperature in the last several decades.

\section{Conclusions}

By combining DSI and NDVI data, this study firstly presented a method of building five buffers for each weather station. Then, using a bivariate correlation model, the average NDVI values in the $20-\mathrm{km}$ buffer were chosen to explain the changes in DSI, since the values in both the spring and summer had higher correlation coefficients with the DSI in the $20-\mathrm{km}$ buffer than the other buffers. Here, the DSI was defined comprehensively, taking into account the frequency, duration and visibility of dust events.

Based on developing a concept model for explaining the changes in DSI, this study thinks that vegetation and wind speed have a direct effect on DSI. These variables were used to interpret the changes in DSI, using a panel data-analysis method. This study found some interesting results:

First, there is a clear relationship between the NDVI and the variance in DSI. Furthermore, the relationship weakened as the average NDVI value decreased in the four zones. In the 
SHTZ, the relationship was the strongest, while it was weakest in the dry temperature zone. In the two regions, the models accounted for approximately $24.9 \%$ and $8.6 \%$ of the variance in the DSI, respectively. Thus, it may be more urgent and effective to strengthen reforestation and re-vegetation to decrease DSI and reduce the damage caused by dust events in the areas with higher vegetation index (e.g., the sub-humid temperate zone) in the northern China, because these areas have a higher population density and strong human activities.

Second, the condition of the vegetation in the summer of the previous year had a far more significant effect on the changes in DSI than that in the spring of the current year, because the latter can not fully reflect the changes in vegetation index. Moreover, the changes in the NDVI values in the summer were much larger than that in the spring. For instance, the average of the NDVI values in the $20-\mathrm{km}$ buffer of 186 stations increased by $19.4 \%$ in the summer from 1983 to 2003, while the value only increased by $4.3 \%$ in the spring. The faster increase in vegetation conditions had more significant effects on the changes in DSI in the summer.

In addition, in the SDTZ, an uneven distribution of vegetation may decrease the intensity of dust storm, according to the model result in this study. This may be worthy of further study in the future.

\section{References}

Cook B I, Miller R L, Seager R, 2009. Amplification of the North American "Dust Bowl” drought through human-induced land degradation. PNAS, 106(13): 4997-5001.

Cyranoski D, 2003, China plans clean sweep on dust storms, Nature, 421(9): 101.

Environmental \& Ecological Science Data Center for West China (EESDC), 2013. The distribution map of desert land and sandy land. http://westdc.westgis.ac.cn.

Duan H, Yan C, Tsunekawa A et al., 2011. Assessing vegetation dynamics in the Three-North Shelter Forest region of China using AVHRR NDVI data. Environ. Earth Sci., 64: 1011-1020.

D'Odorico P, Bhattachan A, Davis K et al., 2013. Global desertification: Drivers and feedbacks. Advances in Water Resources, 51: 326-344.

Engelstaedter S, Kohfeld K E, Tegen I, Harrison S P, 2003. Controls of dust emissions by vegetation and topographic depressions: An evaluation using dust storm frequency data. Geophysical Research Letters, 30(6): 1294. doi: 1210.1029/2002GL016471.

Fischer E V, Hsu N C, Jaffe D A et al., 2009. A decade of dust: Asian dust and springtime aerosol load in the U.S. Pacific Northwest. Geophysical Research Letters, 36: L03821. doi: 03810.01029/02008GL036467.

Gong S L, Zhang X Y, Zhao T L et al., 2004. Sensitivity of Asian dust storm to natural and anthropogenic factors. Geophysical Research Letters, 31: L07210. doi: 07210.01029/02004GL019502, 012004.

Goudie A S, 2009. Dust storms: Recent developments. Journal of Environmental Management, 90: 89-94.

Kimura R, 2012. Factors contributing to dust storms in source regions producing the yellow-sand phenomena observed in Japan from 1993 to 2002. Journal of Arid Environments, 80: 40-44.

Liu G, Park S-U, 2007. The logarithm-linear relationship of the occurrence frequency to the duration of sand-dust storms: Evidence from observational data in China. Journal of Arid Environments, 71: 243-249.

Liu X, Yin Z, Zhang X et al., 2004. Analyses of the spring dust storm frequency of northern China in relation to antecedent and concurrent wind, precipitation, vegetation, and soil moisture conditions. Journal of Geophysical Research, 109: doi: 10.1029/2004JD004615.

Liu Y, Liu R, 2015. Climatology of dust storms in northern China and Mongolia: Results from MODIS observations during 2000-2010. Journal of Geographical Sciences, 25(11): 1298-1306.

McTainsh G, Chan Y-C, McGowan H et al., 2005. The 23rd October 2002 dust storm in eastern Australia: 
Characteristics and meteorological conditions. Atmospheric Environment, 39: 1227-1236.

McTainsh G H, Leys J F, O'Loingsigh T et al., 2011. Wind erosion and land management in Australia during 1940-1949 and 2000-2009 (Report), 45pp. Canberra: Department of Sustainability, Environment, Water, Population and Communities.

McTainsh G H, Lynch A W, Tews E K, 1998. Climatic controls upon dust storm occurrence in eastern Australia. Journal of Arid Environments. 39: 457-466.

O'Loingsigh T, McTainsh G H, Tews E K et al., 2014. The Dust Storm Index (DSI): A method for monitoring broadscale wind erosion using meteorological records. Aeolian Research, 12, 29-40.

Prospero J M, Bullard J E, Hodgkins R, 2012. High-latitude dust over the north Atlantic: Inputs from icelandic proglacial dust storms, Science, 335: 1078-1082.

Prospero J M, Lamb P J, 2003. African droughts and dust transport to the Caribbean: Climate change implications. Science, 302: 1024-1027.

Shao Y, Dong C H, 2006. A review on East Asian dust storm climate, modelling and monitoring. Global and Planetary Change, 52: 1-22.

Tan M, Li X, Xin L, 2014. Intensity of dust storms in China from 1980 to 2007: A new definition. Atmospheric Environment, 85: 215-222.

Tan S-C, Shi G Y, Wang H, 2012. Long-range transport of spring dust storms in Inner Mongolia and impact on the China seas. Atmospheric Environment, 46: 299-308.

Torita H, Sato H, 2007. Relationship between shelterbelt structure and mean wind reduction. Agricultural and Forest Meteorology, 145: 186-194.

Wang X, Dong Z, Zhang J, Liu L, 2004. Modern dust storms in China: An overview. Journal of Arid Environments, 58: 559-574.

Wang X, Zhang Y, Jian J et al., 2009. Effects of spring-summer grazing on longitudinal dune surface in southern Gurbantunggut Desert. Journal of Geographical Sciences, 19: 299-308.

Xiao F, Zhou C, Liao Y, 2008. Dust storms evolution in Taklimakan Desert and its correlation with climatic parameters. Journal of Geographical Sciences, 18: 415-424.

$\mathrm{Xu}$ X, Levy J K, Lin Z et al., 2006. An investigation of sand-dust storm events and land surface characteristics in China using NOAA NDVI data. Global and Planetary Change, 52: 182-196.

Yang B, Bräuning A, Zhang Z et al., 2007. Dust storm frequency and its relation to climate changes in Northern China during the past 1000 years. Atmospheric Environment, 41: 9288-9299.

Yao Z, Xiao J, Li C et al., 2011. Regional characteristics of dust storms observed in the Alxa Plateau of China from 1961 to 2005. Environ. Earth Sci., 64: 255-267.

Yumimoto K, Eguchi K, Uno I et al., 2010. Summertime trans - Pacific transport of Asian dust. Geophysical Research Letters, 37(18) : L18815. doi: 18810.11029/12010GL043995, 042010.

Zhu C, Wang B, Qian W, 2008. Why do dust storms decrease in northern China concurrently with the recent global warming? Geophysical Research Letters, 35: L18702. doi: 18710.11029/12008GL034886, 032008. 